\title{
Observations on Primary School Children's Behavior after School by Using the Global Positioning System
}

\author{
Shohei Sugihara ${ }^{1}$, Daisuke Matsushita ${ }^{* 2}$ and Junzo Munemoto ${ }^{3}$ \\ ${ }^{1}$ M. Eng., Barclays Capital, Ltd., Japan \\ ${ }^{2}$ Associate Professor, Department of Architecture, Okayama University of Science, Japan \\ ${ }^{3}$ Professor, Department of Architecture, Okayama University of Science, Japan
}

\begin{abstract}
Empirical studies of human behavior have been developed mainly using methods of interview or questionnaire by researchers themselves. These studies have successfully obtained adequate results. To observe the behavior of many subjects at once, for many hours and in a wide area however, an alternative technological method is required. The purpose of the authors' work is to develop a better objective method based on measurements, observations and experiments to clarify human behavior in urban environments. The purpose of this paper, as a first step, is to show the availability of research methods concerning children's behavior after school in a suburban city district. The authors asked each primary schooler to wear a compact Global Positioning System receiver after school and to act casually. The collected spatio-temporal data using the Geographical Information System was also analyzed by developing a denoising technique. As a result, the authors clarified the behavior patterns of 35 primary schoolers' regarding transportation devices, travelling routes, distances, time to arrive home and duration of outdoor activity. In conclusion, the authors showed the validity of a research method concerning the collective subjects' behavior for a long period and in a wide area based on more reliable data using the Global Positioning System.
\end{abstract}

Keywords: behavior; primary school children; after-school hours; follow-up study; global positioning system (GPS)

\section{Introduction}

As behaviorists insisted at the beginning of the 20th century, it is still important to use scientific methods as much as possible, based on observation, measurement and experiment, even for the study of human psychology, biology and behavior. In fields such as architectural planning and town planning regarding phenomenon between humans and the built environment, many empirical studies have been successfully developed concerning human behavior in architecture and urban areas. For example, the series of studies by Nishiyama ${ }^{1)}$ (1947) are famous for their practical results in terms of public housing. Hall ${ }^{2}$ (1966) clarified concepts of spatial behavior by observing the activities of humans and animals. The generic methods of these studies have involved both a questionnaire to ascertain people's memories or feelings and a subjective observation by researchers on site. These investigator-mediated measurement methods are

*Contact Author: Daisuke Matsushita, Associate Professor, Department of Architecture, Okayama University of Science,

Ridaicho 1-1, Kita-ku, Okayama, 7000005 Japan

Tel: +81-86-256-9532

E-mail: matsushita@archi.ous.ac.jp

(Received April 8, 2009 ; accepted February 1, 2010) suitable concerning the detailed investigation of individual phenomenon. However, these methods have to depend on the subject's reliability of memory, ability of description and sincerity. These subjective data may be very accurate and significant at times but they may be significantly inaccurate at other times. It has therefore become necessary to develop objective means in order to acquire significant human data by a noninvasive approach with little physical and mental burden.

At the beginning of this study, in order to gain useful knowledge regarding architectural planning and town planning by considering human behavior in urban areas, the authors conceived a method to acquire basic spatio-temporal data of subjects using GPS by observing ground objects from high altitudes. The authors expect to clarify the collective behavior of subjects at constant accuracy concerning when, where, who and what they are doing, by simplifying them to coordinate points in a three dimensional urban space. This approach owes much to the technological growth of measuring devices allowing sufficient positioning accuracy over many hours even with generic devices. A GPS wearer can act as usual without burden because they carry only a small lightweight device in their pocket. As each GPS device records a unique 
identification code, time and position at constant time intervals, the GPS wearer's behavior is ascertainable at a certain level from these data. For example, it is possible to identify if a wearer is staying, walking, running, riding a bike or car from the data based on travelling speed, acceleration and route on a map. If they stay at urban facilities such as a park or a library, they are expected to use them for the usual purposes.

The purpose of this paper is to show the availability of an approach to clarify the collective behavior patterns of 35 primary schoolers after school in an urban space by acquiring their spatio-temporal data using GPS devices. To the best of the authors' knowledge, few studies have yet been carried out on collective children using this kind of approach, though some have been conducted on wild animals in the ethological field. As this study obtained the cooperation of human subjects, privacy was a necessary issue. The authors obtained their consent to wear GPS devices, and managed data anonymously based on an appropriate ethical perspective.

Conventional researches of human behavior were often based on a questionnaire or observation of subjects by researchers (Table 1.).

Table 1. Conventional Investigation Method of Behavior

\begin{tabular}{l|l}
\hline Name & Abstract \\
\hline Questionnaire & $\begin{array}{l}\text { Researcher asks subjects to answer the } \\
\text { questionnaire in writing. } \\
\text { Researcher interviews or has a dialogue with } \\
\text { subjects. }\end{array}$ \\
\hline Observation & $\begin{array}{l}\text { Researcher observes collective subjects at } \\
\text { fixed point. }\end{array}$ \\
\hline & $\begin{array}{l}\text { Researcher observes a specific subject by } \\
\text { following-up. }\end{array}$ \\
\hline
\end{tabular}

A survey of the current behavior of primary school children after school was conducted by a questionnaire in Japan (Fukaya et al., 2006) ${ }^{3)}$. Utilizations of parks by children were investigated by interview (Kanda, T. $1998)^{4)}$, while the side-tripping behavior of children was surveyed by a follow-up investigation (Miwa, N. et al. 2001) $)^{5}$. A qualitative study was carried out concerning parents' perceptions of the influences on children's active free-play (Veitch, J. et al., 2006) ${ }^{6}$, and parents' conceptions of social dangers to children in the urban environment were also investigated (Blakely, K., $1994)^{7)}$. Some recent studies have suggested using GPS devices for observation of human or animal travelling pathways (Nomura ${ }^{8)}$, et al., 2006, Yamamoto ${ }^{9}$, et al. 2006). The authors' group studied the activities of children or adults in urban areas (Tatenami et al. 2006 , etc. $)^{10-20)}$. In order to prevent crime, children's activities after school were also surveyed (Amemiya et al. 2009) ${ }^{21)}$. Unlike the studies made extensively based on investigator-mediated methods, little attention was given to the approach using measuring devices such as GPS to measure collective subjects' behavior objectively at a certain accuracy, at the same time, over a long period and wide area.

\section{Methods}

\subsection{Data management of GPS devices}

The authors downloaded GPS data of the NMEA format to standalone $\mathrm{PC}$, and converted it to a vector data set using Geographical Information System (GIS) (Fig.1.).

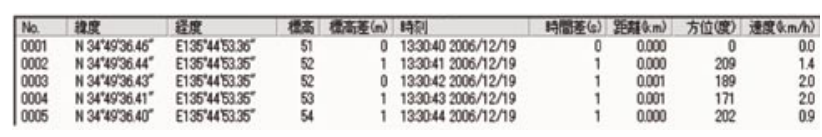

Fig.1. Example of GPS Data Converted by GIS

(From left) Data No., Latitude, Longitude, Altitude, Time, Distance, Orientation, Speed. (One row stands for one positioning data per one second.)

The distance between two positioning points is calculated by spherical trigonometry formula. Travelling speed between two positioning points is calculated from the distance and the interval time.

\subsection{Denoising}

When subjects are indoors, position-fix accuracy becomes worse. The authors filtered out wrong positioning data as noises from a continuous travelling trajectory.

$$
\alpha_{m}=\frac{V_{m}-V_{m-1}}{T_{m}-T_{m-1}} \cdots(1)
$$

(1) An average change of speed is calculated from a change of speed and interval time between two continuous positioning points.

$\alpha_{m}$ : Change of Speed $\left[\mathrm{km} / \mathrm{s}^{2}\right], V_{m}$ : Speed $[\mathrm{km} / \mathrm{s}], T_{m}$ : Time [s]

(2) A wrong point is picked up if its average change of speed is more than $10\left[\mathrm{~km} / \mathrm{s}^{2}\right]$. The number of wrong points are counted in 180 second intervals.

$N_{m}$ : Number of $\alpha_{m}\left(\alpha_{m}>10 \mid T<t<T+180[\mathrm{~s}]\right) \ldots$ (2)

(3) The sequence of positioning points is noise if there are more than two wrong points in 180 second intervals.

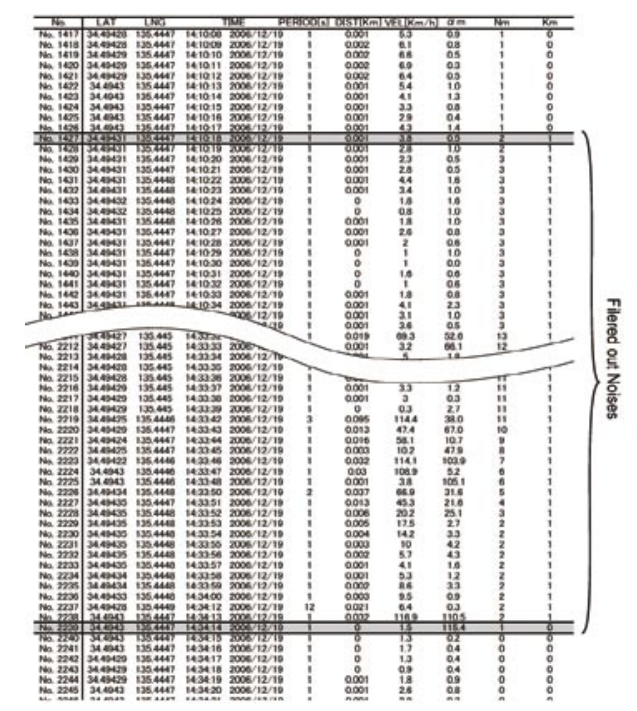

Fig.2. Example of Filtered Noise Data (No.1427 - 2239) 


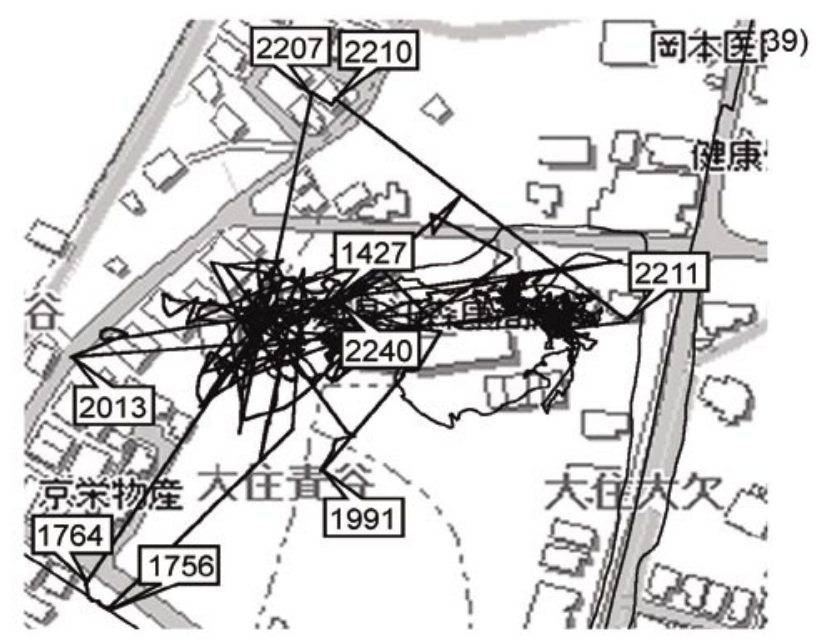

Fig.3. Example of Noise Positioning Point (Before Denoising)

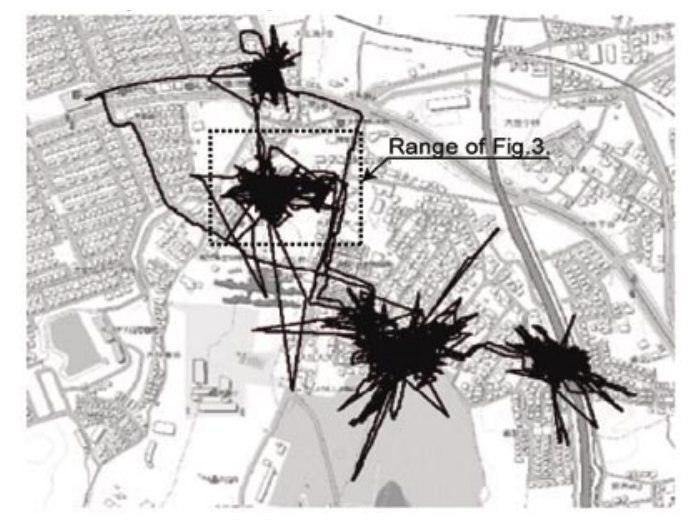

Fig.5. Example of Noise Positioning Point (Before Denoising)

$K_{m}=1(\mathrm{Nm} \geqq 2)$ : Points from $T$ to $T+180$ are noise, ...(3)

$=0(\mathrm{Nm} \leqq 1)$ : Points from $T$ to $T+180$ are not noise

\subsection{Investigation of primary schoolers' behavior}

1) Subjects

Table 2. Subjects' Grades and Gender

\begin{tabular}{|c|c|c|c|c|c|c|}
\hline & $1^{\mathrm{st}}: 2^{\text {nd }}$ & $3^{\text {rd }}$ & $4^{\text {th }}$ & $5^{\text {th }}$ & $6^{\text {th }}$ & Total \\
\hline Male & 2 & 5 & 12 & 5 & 2 & 16 \\
\hline Female & 0 & 6 & 5 & 1 & 2 & 19 \\
\hline Total & 7 & 11 & 7 & 6 & 4 & 35 \\
\hline
\end{tabular}

When primary school children are at school, on their way between school and home or at home, they are watched by parents and teachers. However their behavior after school is less obvious. They are not constrained in this period so that they tend to act on their own initiative. The basic data of their behavior are required by such fields as town planning and facilities planning. The authors conducted an investigation of

Table 3. Conditions of Investigation

\begin{tabular}{|l|l|}
\hline Investigation date & Day with no afternoon classes in Dec. \\
\hline Investigation time & From 1:00 p.m. to 10:00 p.m. \\
\hline Weather & Fine \\
\hline Temperature & $11.2 \mathrm{C} /-1.9 \mathrm{C}$ \\
\hline Average temp. & $10.5 \mathrm{C}$ \\
\hline Sunset time & $4: 48$ p.m. \\
\hline Wind speed & $1 \mathrm{~m} / \mathrm{s}$ \\
\hline
\end{tabular}

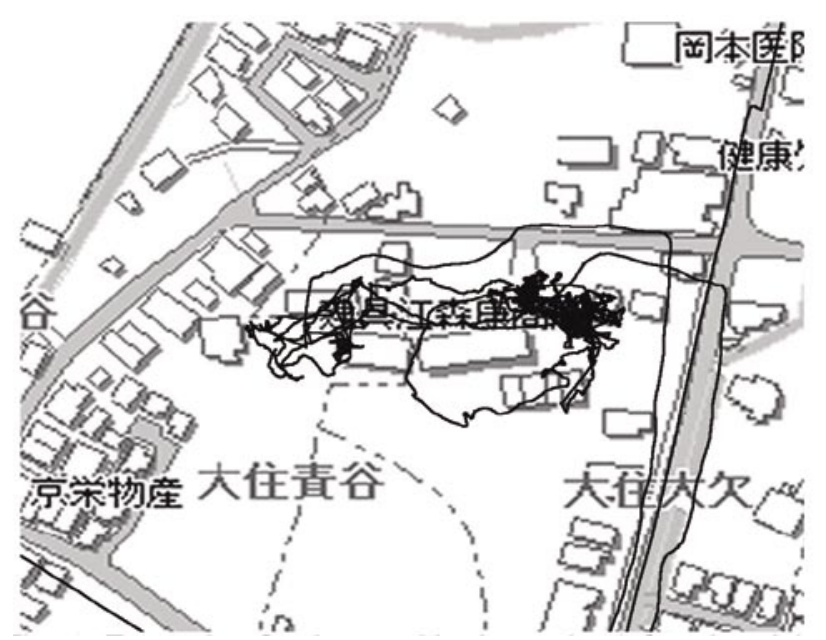

Fig.4. Example of Noise Positioning Point (After Denoising)

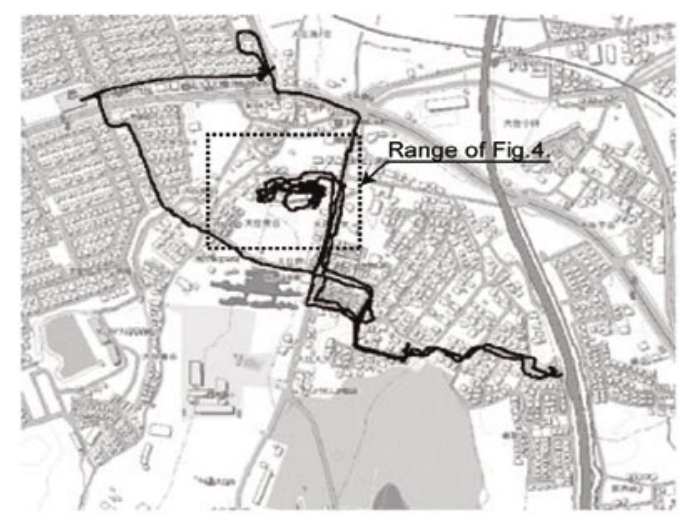

Fig.6. Example of Noise Positioning Point (After Denoising)

primary schoolers' behavior after school.

2) Conditions of investigation

3) Investigation flow

The primary schoolers wear GPS devices when school is over. They act casually as usual and when they go to bed, they take the GPS off.
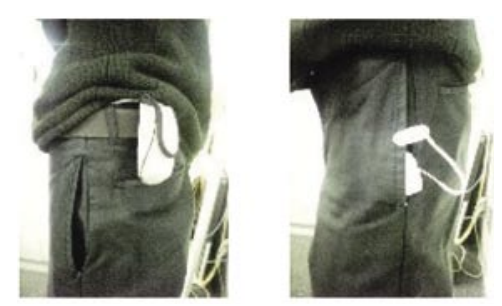

Fig.7. They Wear GPS using a Pouch (Left) or Strap (Right)

\section{Results}

One GPS device did not record normal data. The authors finally obtained the GPS data of 34 subjects.

Most travelling trajectory was seen inside the school district. Travelling outside the school district was by car because the travelling speed was more than $30 \mathrm{~km} / \mathrm{h}$. The authors ascertained the travelling means based on travelling speed and route on the map (Fig.9.).

Thirty-three out of 34 subjects went outside of the home after school. After seven o'clock the number of 


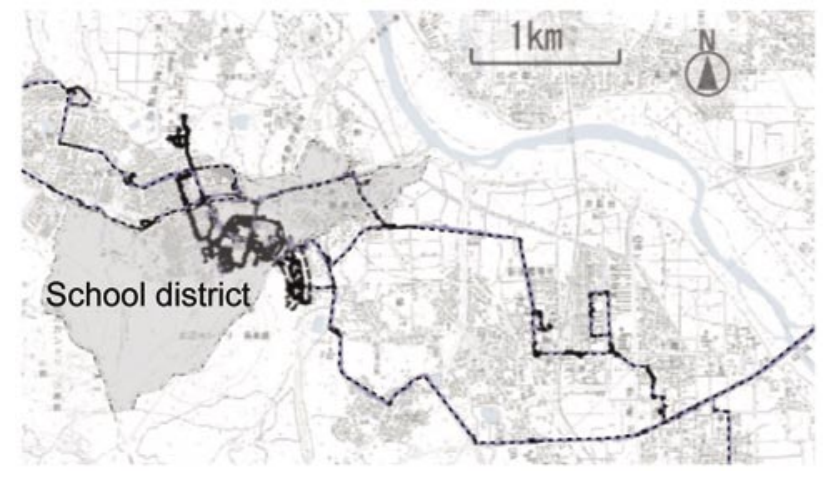

Fig.8. Travelling trajectory of all subjects. The line stands for movement of less than $30 \mathrm{~km} / \mathrm{h}$. The dashed line stands for movement of more than $30 \mathrm{~km} / \mathrm{h}$. The gray area is the school district

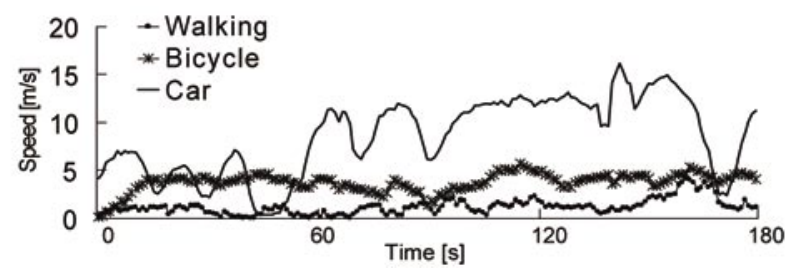

Fig.9. Transition of Travelling Speed

subjects outside the school district is greater than those inside (Fig.10.).

Twenty subjects did not use a car and, except for two, did not go out of the school district. On the other hand, 14 subjects, who used a car, did go out of the

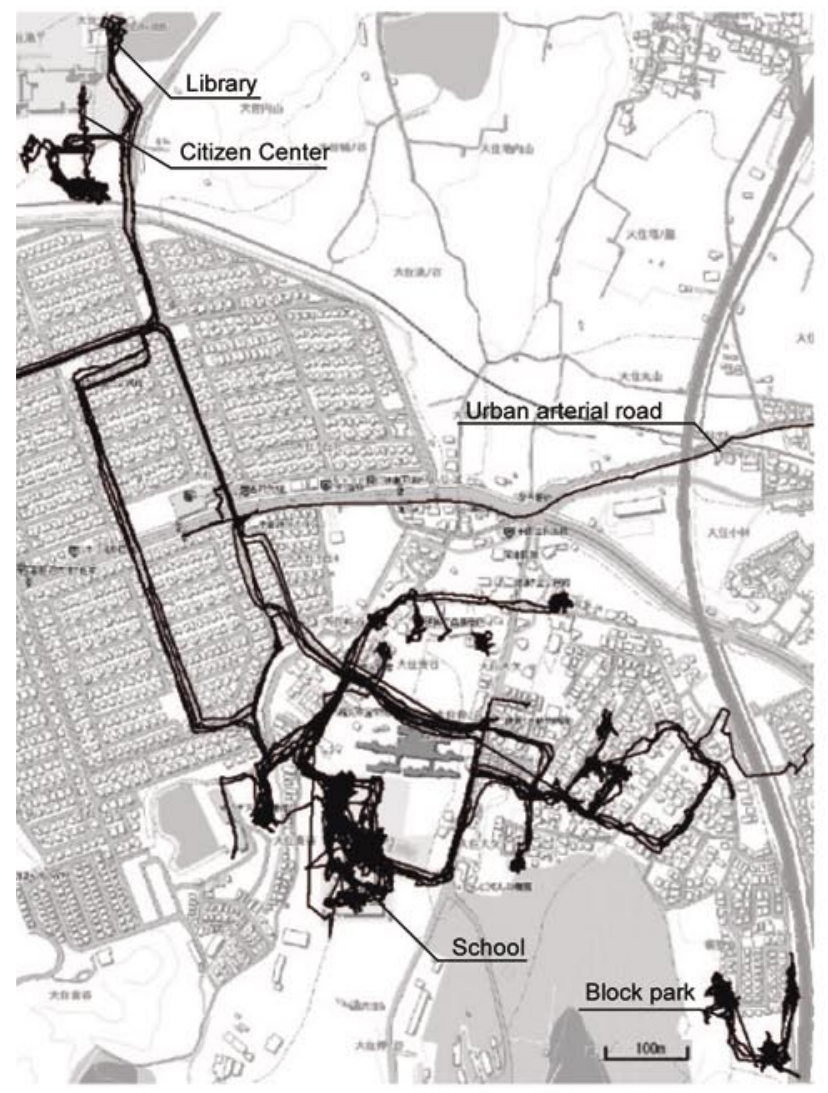

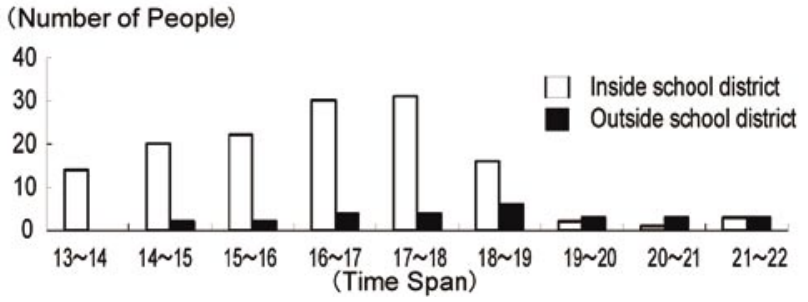

Fig.10. Number of Subjects Inside or Outside the School District

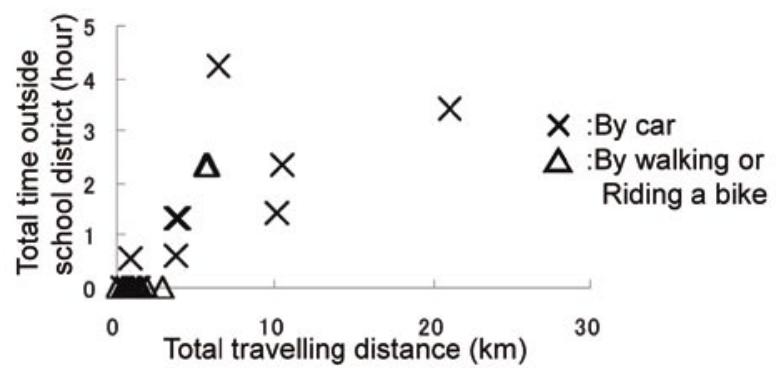

Fig.11. Total Travelling Distance and Total Time Outside the School District

school district.

Subjects in lower grades went to public facilities such as library and citizen center in a wide area. Some of them went back to the school after classes and played there. Meanwhile, the field of activities of the subjects in lower grades was narrower.

The authors asked each subject how many people they play with per day after school. Most of the subjects who play with other schoolchildren did not

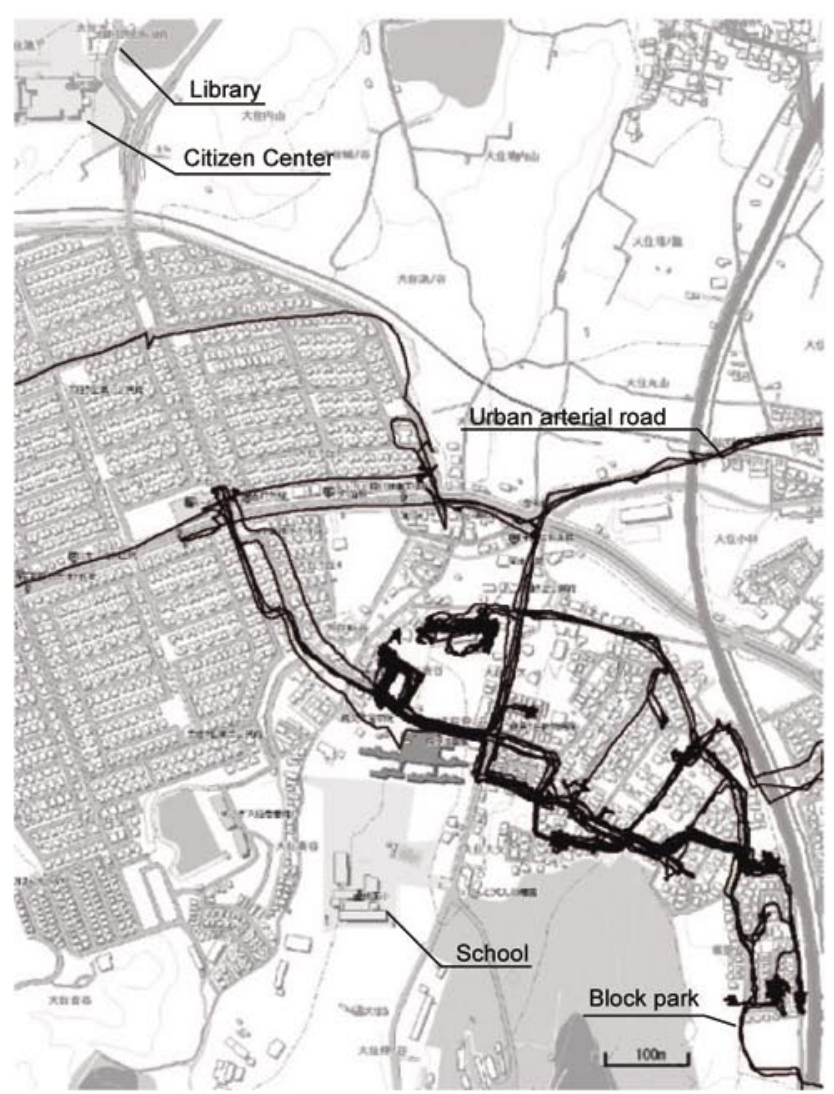

Fig.12. Travelling Trajectory of Schoolchildren in Lower Grades (Left) and One in Higher Grades (Right) 


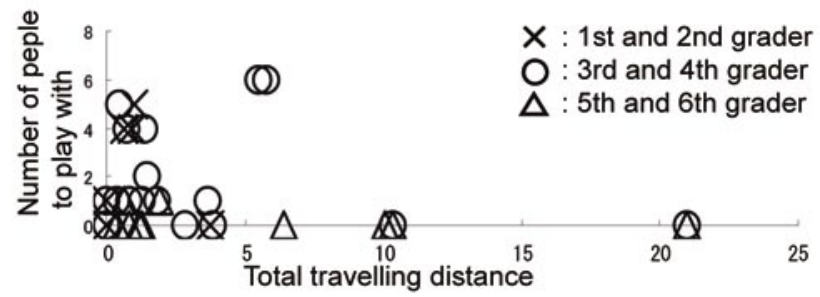

Fig.13. Total Travelling Distance and Number of People to Play with

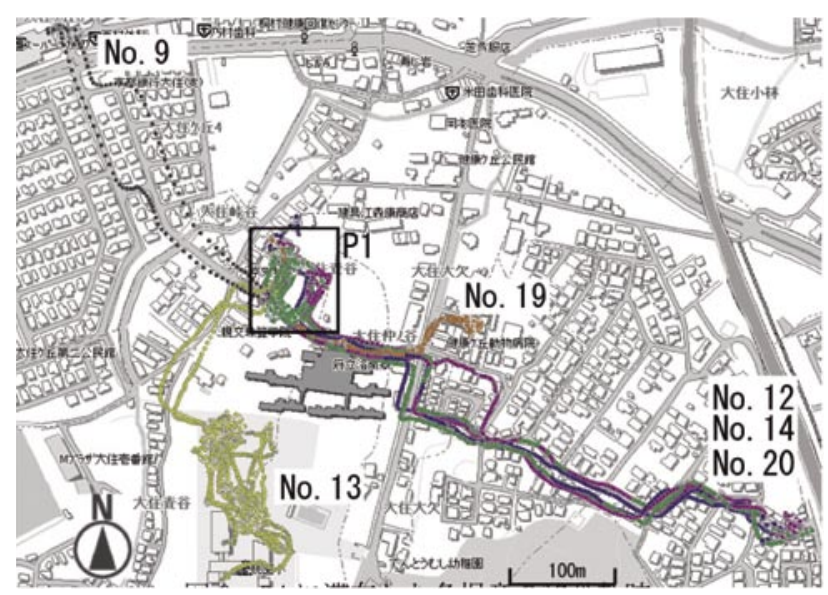

Fig.14. Travelling Trajectory of Subjects Who Played at P1

travel more than $5 \mathrm{~km}$, except two subjects who went to public facilities. First and 2nd graders did not travel more than $5 \mathrm{~km}$, most of them play around their home. The number of people who 3rd and 4th graders play with was not more than four. Meanwhile the number of people who 5th and 6th graders play with was not more than one. The subjects who used a car and went out of the school district did not play with other schoolchildren. Higher graders went outside of the home at a later time.

Collective subjects stayed at some specific places in the site. For example, six subjects stayed at P1, which is a residential area (Fig.14.).

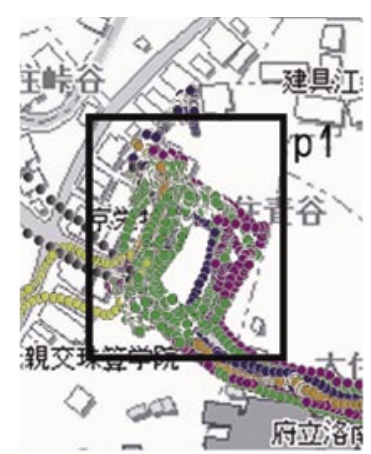

Fig.15. Close-up of P1

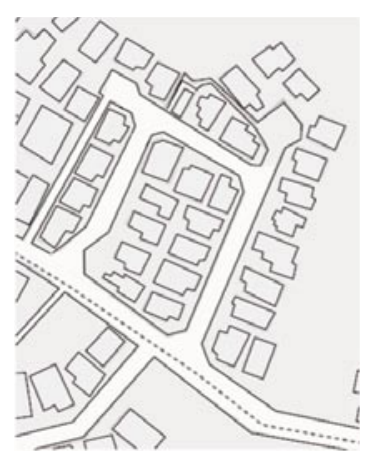

Fig.16. Street Map of P1
The street with a dashed line has a lot of car traffic, and other streets have dead-ends (Fig.15.). Many subjects played in these dead-end streets. The subjects No. 9, 12, 13, 19 and 20, who played in the dead-end streets stayed outside the home for a longer time than other subjects.

\section{Conclusions}

The authors have presented an approach to acquire collective behaviors at one time, for many hours and over a wide area. The results at this stage are very limited because the investigation was conducted on only 35 subjects during one day. However the authors show the acquired knowledge as below.

- The travelling trajectory by walking did not cross outside the school district (Fig.8.).

- After 7 p.m. the number of subjects outside the school district became larger than those inside it (Fig.10.).

- They mainly walked or rode bikes inside the school district, and used cars outside of it (Fig.8.).

- Subjects who used a car and travelled more than 5 $\mathrm{km}$ did not play with other children (Fig.13.).

- Low graders living near the school went to the school again and played there (Fig.12.).

- Low traffic roads with dead-ends were used for play activity (Figs.14., 15., 16.).

It is also important to seek a better method of acquiring the primary data. The measuring method of human behavior by devices such as GPS allows us to acquire objective data with a constant accuracy without relying on the investigators' or subjects' individual current condition by the human-mediated data exchange process. The significance of this paper is shown because the resultant knowledge refers to the specific time and place of the children's behavior.

\section{Acknowledgement}

This paper is based on the master thesis of Kyoto University (Sugihara 2007) ${ }^{22)}$.

This study is supported by KAKENHI (18650206).

\section{References}

1) Nishiyama, U. (1947) Korekara no Sumai (in Japanese), Sagamisyobo.

2) Hall, E. (1966) The Hidden Dimension, Doubleday \& Company, Inc., New York.

3) Fukaya, M., Takahata, M. and Fukaya K. (2006) Ima Kodomono Houkagowa Dounatte Irunoka (in Japanese), Kitaojishobo.

4) Kanda, T. (1998) A study on utilization time of play-lot. Journal of Architecture, Planning and Environmental Engineering, (499), pp.49-56.

5) Miwa, N. Senda, M. and Yata, T. (2001) Spatial capacity to generate children's play spaces: Analysis of data from state-ofthe-art surveys of children's play environments in urban areas of major cities. Journal of Architecture, Planning and Environmental Engineering, (539), pp.187-194.

6) Veitch, J. et al. (2006) Where do children usually play? A qualitative study of parents' perceptions of influences on children's active free-play. Health \& Place, (12), pp.383-393.

7) Blakely, K. (1994) Parents' conceptions of social dangers to children in the urban environment, children's environments, (11), pp.21-35.

8) Nomura, Y. and Kishimoto, T. (2006) The Analysis for Visitors' Behavior and Activity Using GPS and GIS in Kamakura City. New Frontiers of Architecture and Urbanism in Information Driven Society, (4), pp.72-77. 
9) Yamamoto, Y., Ito, H., Ono, R. and Shimomura, A. (2006) A Study on the Pattern of User's Behavior in Shinjyuku Gyoen National Garden Using Handy GPS(Papers of the 24th Scientific Research Meeting), journal of the Japanese Institute of Landscape Architecture, 69(5), pp.601-604.

10) Tatenami, T., Matsushita D. and Munemoto J. (2006) Transition of Level of Anxiety in Wayfinding with Pedestrian Navigation System on Mobile Telephone, Journal of architecture and planning (608), Architectural Institute of Japan, pp.59-64.

11) Matsuura, T., Munemoto, J. and Matsushita D. (2007) Children's Behavior After School by Analysing Spatial Temporal Trajectory with GIS, Proceedings of the Thirtieth Symposium on Computer Technology of Information, Systems and Applications, Architectural Institute of Japan, pp.201-204.

12) Matsushita, D., Sugihara, S., Munemoto, J., Matsuura, T. and Nanzai, K. (2007) Observation Method of Elementary School Children's Spatio Temporal Trajectory after School by Using Global Positioning System Data Logger, Proceedings of the Thirtieth Symposium on Computer Technology of Information, Systems and Applications, Architectural Institute of Japan, pp.205-208.

13) Kan, U., Nanzai, K., Munemoto, J., Matsushita, D. and Yukawa, K. (2008) A Study On Outdoor Behavior of Prinary School Children after School Using GPS in Nagahama City Part1, Summaries of technical papers of Annual Meeting Architectural Institute of Japan. E-1, Architectural planning and design I, Building types and community facilities, planning and design method building construction system human factor studies planning and design theory, pp.865-866.

14) Nagata, M., Nanzai, K., Munemoto, J., Matsushita, D. and Ishikawa, M. (2008) The study on outdoor behavior of G elementary school children during after-school hours by using GPS Part 2 Analysis sampled data on children's behavior, Summaries of technical papers of Annual Meeting Architectural Institute of Japan. E-1, Architectural planning and design I, Building types and community facilities, planning and design method building construction system human factor studies planning and design theory, pp.875-876.

15) Ishikawa, M., Nanzai, K., Munemoto, J., Matsushita, D. and Nagata, M. (2008) The study on outdoor behavior of G elementary school children during after-school hours by using GPS Part 1 The methods to survey of behavior by using GPS and to correct errors in the obtained data from the survey, Summaries of technical papers of Annual Meeting Architectural Institute of Japan. E-1, Architectural planning and design I, Building types and community facilities, planning and design method building construction system human factor studies planning and design theory, pp.873-874.

16) Zhang, X., Nanzai, K., Matsushita, D. and Munemoto, J. (2008) Investigation on Children's Behavior After School by Analyzing Spatial Temporal Trajectory with GPS, Summaries of technical papers of Annual Meeting Architectural Institute of Japan. E-1, Architectural planning and design I, Building types and community facilities, planning and design method building construction system human factor studies planning and design theory, pp.871-872.

17) Yukawa, K., Nanzai, K., Munemoto, J., Matsushita, D. and HAN, Y. (2008) The Study of Outdoor Behavior on Primary School Children After School Using GPS in Nagahama City Part2, Summaries of technical papers of Annual Meeting Architectural Institute of Japan. E-1, Architectural planning and design I, Building types and community facilities, planning and design method building construction system human factor studies planning and design theory, pp.867-868.
18) Matsushita, D., Munemoto, J., Yoshida, T., Son, K., Matsuura, T. and Nanzai, K. (2007) Investigation of Elementary School Children's Spatio-Temporal Trajectory after School in Maizuru City by using GPS Data Logger, Summaries of technical papers of Annual Meeting Architectural Institute of Japan. E-1, Architectural planning and design I, Building types and community facilities, planning and design method building construction system human factor studies planning and design theory, pp.1043-1044.

19) Nanzai, K., Sugihara, S., Munemoto, J., Matsushita, D and HUTAE, T. (2007) A Study on Outdoor Behavior of Primary School Children after Leaving School by Using GPS Part2,Summaries of technical papers of Annual Meeting Architectural Institute of Japan. E-1, Architectural planning and design I, Building types and community facilities, planning and design method building construction system human factor studies planning and design theory, pp.1041-1042.

20) Futae, T., Sugihara, S, Munemoto, J., Matsushita, D., Nanzai, K. (2007) The Study of Outdoor Behavior on Primary School Children After School Using GPS Part1, Summaries of technical papers of Annual Meeting Architectural Institute of Japan. E-1, Architectural planning and design I, Building types and community facilities, planning and design method building construction system human factor studies planning and design theory, pp.1039-1040.

21) Amemiya, M., Saito, T., Kikuti, S., Shimada, T. and Harada Y. (2009) Identifying the spatio-temporal characteristics of children's after school activities and adults' neighborhood watch activities using GPS data, (Papers of the 27th Scientific Research Meeting), journal of the Japanese Institute of Landscape Architecture (27), 72(5), pp.747-752.

22) Sugihara, S. (2007) Behavior of elementary school children after school using Global Positioning System, Kyoto University Master Thesis. 